\title{
An Observational Study to Evaluate Quality of Life in Patients with Melasma in a Tertiary Level Hospital of Pokhara
}

\author{
Pudasaini $\mathbf{P}^{1}$, Neupane $\mathbf{S}^{2}$ \\ ${ }^{1}$ Resident, ${ }^{2}$ Professor, Department of Dermatology, Gandaki Medical College, Pokhara, Nepal.
}

\begin{abstract}
Introduction: Melasma is an acquired hyper melanosis that becomes more pronounced after sun exposure. Centro facial which is the commonest pattern followed by Malar and Mandibular are three clinical patterns of Melasma. Genetic influences, exposure to UV radiation, pregnancy, hormonal therapies, contribute to the pathogenesis of melasma. Melasma may considerably have significant effect on quality of life of patients.

Objectives: The present study was conducted to evaluate the effects of melasma in quality of life (QoL) in the form of DLQI (Dermatology Life Quality Index) and severity of melasma according to Melasma Area and Severity Index (MASI).

Materials and Methods: This is a hospital based cross-sectional prospective study conducted in 193 Melasma patients in the Department of Dermatology, Venereology and Leprology, Gandaki Medical College and Teaching Hospital, Pokhara from November 2018 to November 2019. MASI score was calculated and the patients were provided with a Nepali version of DLQI to fill up.

Results: This study included 193 patients. Mean age of patients with melasma was $29.4 \pm 8.5$ years with maximum reported age of 59 years. The Mean age of onset of disease was 26.5 years. The Mean age of onset of disease had little impact on DLQI. The mean DLQI score was $10.9 \pm 5.9$, thus indicating "very large effect on patient's life". The mean MASI score was $6.6 \pm 5.2$. It was found that there was no correlation between severity of disease and DLQI scores $(p=0.317)$

Conclusion: Melasma commonly affected females during second and third decades of life. It had a very large effect on patient's life as assessed by DLQI.
\end{abstract}

Key words: Melanosis; Quality of Life; Severity of Illness Index; Ultraviolet Rays

\section{Introduction}

$\mathrm{M}$ elasma is an acquired hyper melanosis that becomes more pronounced after sun exposure. ${ }^{1}$ It's dependent on use of oral contraceptives or pregnancy in females. ${ }^{2,3}$ The exact pathogenesis of melasma is unknown. ${ }^{4}$ Genetic influences, exposure to UV radiation, pregnancy, hormonal therapies, contribute to the pathogenesis of melasma. ${ }^{5}$ AlphaMelanocyte Stimulating Hormone (MSH) mediated activation of cyclic AMP and increased response of human melanocyte to UVB has been implicated in hyperpigmentation of melasma lesions. ${ }^{6}$ Altered vessels in melasma due to VEGF as major angiogenic factor has also been implicated in development of

Funding: No

Conflict of Interest: No

\section{Address of Correspondence}

Prajwal Pudasaini

Department of Dermatology, Gandaki Medical College, Pokhara, Nepal.

E-mail: prajwalpudasaini@gmail.com pigmentation. ${ }^{7}$ All people can be affected by melasma with Asian, Hispanics and Afro-Americans females being the most commonly affected ones. ${ }^{8}$ Forehead, cheeks, nose, chin, upper lip, neck are common sites of predilection. Women are more commonly affected than men. Women who presented with melasma at the age of less than 30 years had more severe disease. It's particularly more common in Fitzpatrick skin types IV and V with predominantly Centro facial pattern. ${ }^{9}$

Submitted: $9^{\text {th }}$ December 2020

Accepted: $15^{\text {th }}$ January 2021

Published: $20^{\text {th }}$ February 2021

How to cite this article

Pudasaini P, Neupane S. An Observational Study to Evaluate Quality of Life in Patients with Melasma in A Tertiary Level Hospital of Pokhara. Nepal Journal of Dermatology, Venereology \& Leprology 2021;19(1):37-41. https://doi. org/10.3126/njdvl.v19i1.35047.

Licensed under CC BY 4.0 International License which permits use, distribution and reproduction in any medium, provided the original work is properly cited. 
Measurement of QoL is of great importance in dermatology, as direct risk to life may not be caused by the disease, but emotional well-being and social life of the patient can be affected. ${ }^{10}$ As a practicing clinician only the clinical aspect of dermatological disease is taken into consideration, however, studies have shown that adjunctive psychological stress assessment plays an important role in management of these conditions. ${ }^{11}$ Melasma Area and Severity Index (MASI) score has been developed as a reliable and valid means of measuring Melasma severity.

\section{Materials and Methods}

Before starting the study, the proposal was first submitted to the National Health Research Council Ethical Review Board and ethical clearance was taken. This was a hospital based cross-sectional prospective study conducted in 193 Melasma patients in the Department of Dermatology, Venereology and Leprology, Gandaki Medical College and Teaching Hospital, Pokhara. Study population was any patient with clinical features of melasma, fulfilling the inclusion criteria. Patients included in the study were patients presenting to dermatology OPD with melasma, all patients giving consent to participate in the study and referred cases of melasma from other centers. This was a cross-sectional quantitative questionnaire study using "Dermatology Life Quality Index" and MASI score. The age, gender, diagnosis of all patients included in the study were recorded. Mean and Standard Deviation was calculated for the quantitative data. For qualitative variables like gender: frequency and percentage were calculated. The study was conducted from April 2019 to March 2020. The sampling technique that was employed was non-probability convenience sampling. The data was collected on printed proforma, then analyzed using Microsoft excel 2016 and SPSS Version 20.0. for windows. Descriptive statistics were used to describe the frequency, mean, standard deviation with $95 \%$ confidence interval of DLQI. Level of significance was set at $5 \%(p \leq 0.05)$ and power was set at $80 \%$. Dermatology Life Quality Index (DLQI) has been developed as a simple compact practical questionnaire tool for assessment of Quality of Life (QoL) in any disease in routine clinical practice. ${ }^{12}$ Dermatology Life Quality Index (DLQI) describes ten questions in six headings about very basic human concerns which are very simple. DLQI question about sexual difficulties although appropriate in many socio-cultural regions, may be unacceptable in certain sociocultural setting like hilly region of Nepal. ${ }^{13}$
DLQI Scores 0-1 indicates no effect at all on patient's life, 2-5 indicates small effect on patient's life, 6-10 indicates moderate effect on patient's life, 11-20 indicates very large effect on patient's life and score of 21-30 indicates extremely large effect on patient's life. The severity of melasma in each of the four regions (forehead, right malar region, left malar region and chin) is assessed based on three variables: percentage of the total area involved (A), darkness (D), and Homogeneity $(\mathrm{H})$. To calculate the MASI score, the sum of the severity grade for Darkness (D) and Homogeneity (H) was multiplied by the numerical value of the areas (A) involved and by the percentages of the four facial areas (10-30\%).

\section{Results}

This study included 193 patients. Mean age of patients with melasma was $29.4 \pm 8.5$ years with maximum reported age of 59 years. Majority of them were females (79.8\%) and $20.2 \%$ were males. Most of the patients were Married (72\%). Around $50 \%$ were Tibet Mongolians and the remaining were Aryans. Centro facial pattern $(51.3 \%)$ was the commonest pattern observed followed by Malar (37.8 \%) and Mandibular (10.9\%). Most of the patients were Housewives (40.9\%) followed by Students (28.5\%), Businessmen (13\%) and Job holder (9.3\%). The Mean age of onset of disease was 26.5 years. The Mean age of onset of disease had little impact on DLQI. Most patients $(61.1 \%)$ had disease duration of $1-5$ years. Most common aggravating factor was attributed to sunlight (67.4\%), but most of them were unaware (22.8\%) of aggravating factors. Majority of patients had summer exacerbation (62.2\%) of the disease. Stress was also one of the important aggravating factors (6.2\%) of the disease. Most of the melasma patients had history of intake of Oral Contraceptive Pills (OCPs) (39.8\%). Most of the patients (46.6\%) developed melasma during pregnancy in our study. Most of the melasma patients $(34.7 \%)$ in our study were treated with the over-the-counter medications and only few (24.9\%) went to dermatologist for treatment. The mean DLQI score was $10.9 \pm 5.9$, thus indicating "very large effect on patient's life". The mean MASI score was $6.6 \pm 5.2$. It was found that there was no correlation between severity of disease and DLQI scores $(p=0.317)$.

Table: Correlation of DLQI score and MASI

\begin{tabular}{|l|l|}
\hline Correlation between DLQI and MASI \\
\hline Pearson Correlation & 0.072 \\
\hline$p$ value & 0.317 \\
\hline
\end{tabular}




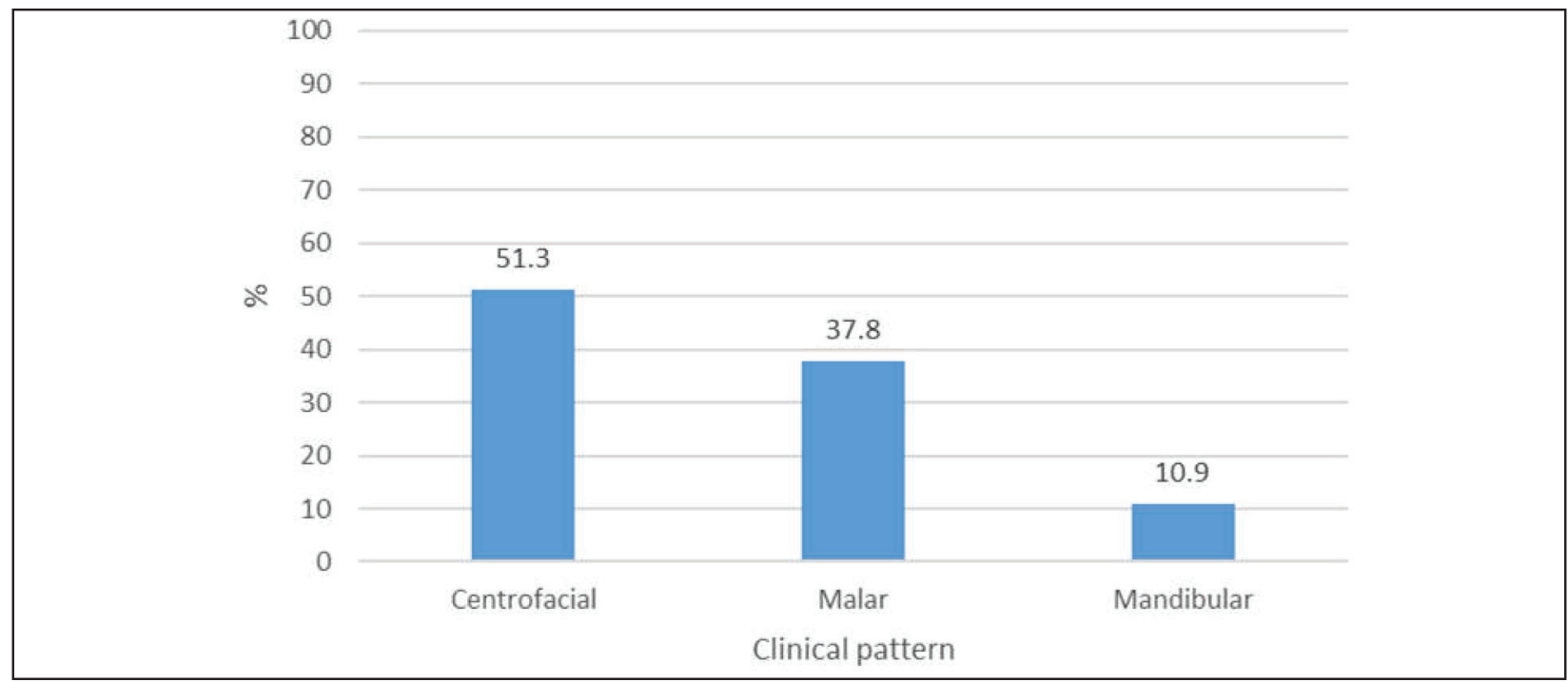

Figure 1: Distribution of melasma patients by clinical patterns $(n=193)$

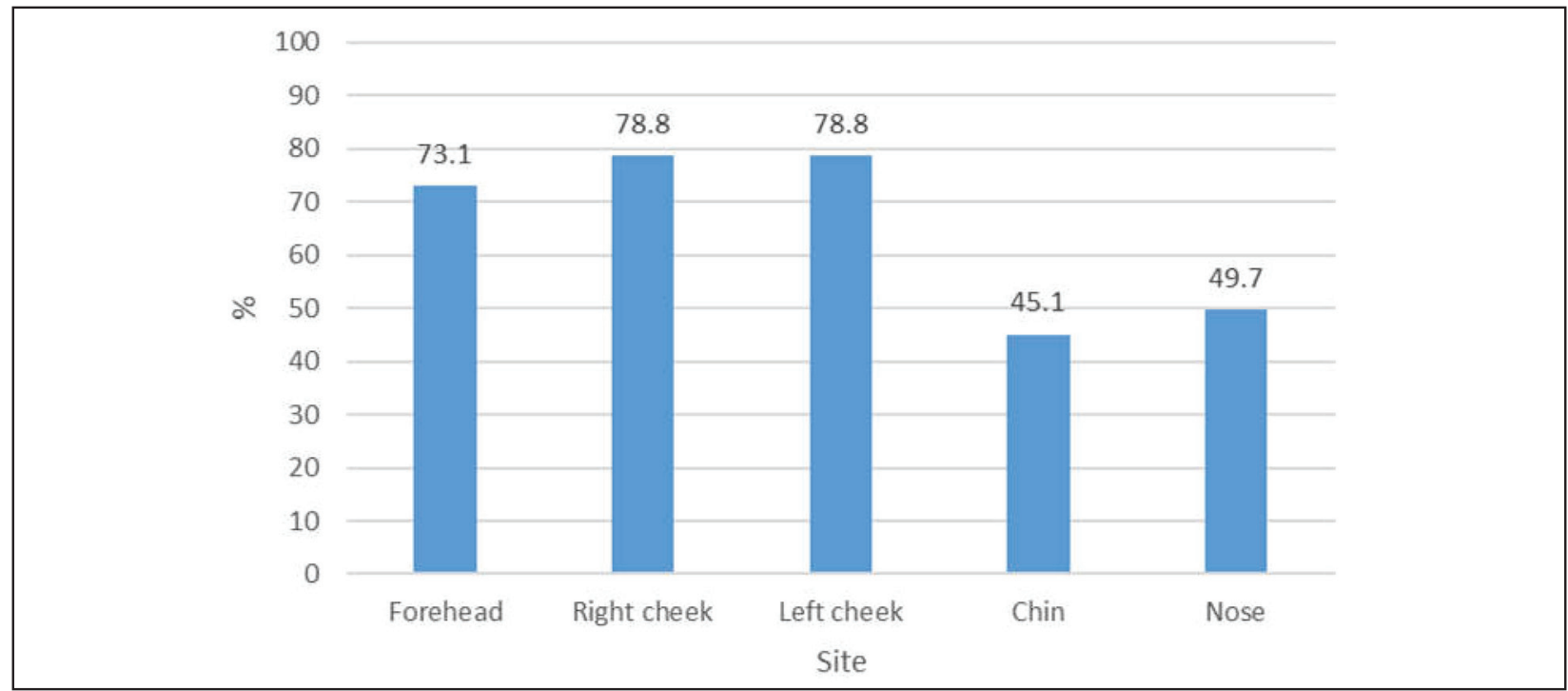

Figure 2: Distribution of melasma patients by sites affected

\section{Discussion}

The Mean \pm SD MASI score for patients with melasma in our study was $6.6 \pm 5.2$ (range 1.1 to 23.6) which was lower than a study from Singapore which showed the mean \pm SD MASI score to be $12.1 \pm 6.5 .{ }^{14}$ It was also lower than a study from Brazil which evaluated 85 women with melasma with mean MASI of $10.6 \pm$ $6.64 .^{15}$

The Mean \pm SD DLQI score for patients with melasma in our study was $10.9 \pm 5.9$ (range 1 to 25 ) which implies "very large effect on patient's life". Similar other study showed higher mean DLQI score of 17.08 with very large effect on patient's life. ${ }^{16}$ Our result was slightly higher than a mean DLQI of $9.92 \pm 7.01$ in a study from India. ${ }^{17}$ Other study from Nepal has shown lower mean DLQI score of $5.64 \pm 5.41$. The lower mean DLQI in this study was postulated to be due to predominantly married female who were housewives and hence lower psychological burden due to the facial pigmentation in housewives. ${ }^{18}$

High DLQI in our study could be attributed to larger percentage of patients in our study using over the counter medication (34.4\%) and hence late presentation with severe disease at our tertiary level hospital. This large DLQI score implies that, even though melasma is devoid of systemic complications, facial pigmentation can have significant effect on daily activities, work and personal relationships in an individual. Also, since majority of the affected female 
patients in our study were in their late 20s, facial appearance can be of great concern in this age and hence the high DLQI seen in our study. Studies have shown that facial involvement and involvement of hands may have significant impact on quality of life as compared to other sites. ${ }^{19}$ Since melasma occurs predominantly over face, it could also be one of the reasons of very large effect on quality of life as evidenced by high DLQI $(10.9 \pm 5.9)$ in our study

Also similar study from Nepal has shown that compared to other dermatological disorder (vitiligo), melasma has higher impact on quality of life of patients. ${ }^{18}$ The lowest mean DLQI reported was 1.46 from one study from India. ${ }^{20}$

In this study, mean DLQI scores for female (11.23 \pm $5.98)$ was higher than that for males $(9.74 \pm 5.56)$. The results were in contrary to a similar study from Nepal which showed mean DLQI score in males $(7.09 \pm 7.04)$ which was higher than for females $(5.46 \pm 5.20){ }^{18}$

A study among male Latino workers showed higher DLQI of 7.5 indicating poor quality of life..$^{21}$ In this study, DLQI for patients of 20-29 years (11.32 \pm 5.71$)$ was higher than the DLQI value of $9.82 \pm 6.18$ in patients of 40-49 years age group. It was similar to a study from turkey which showed higher mean DLQI scores in patients aged $<30$ years $(7.44 \pm 4.99)$ as compared to $4.33 \pm 4.36$ in those above 30 years. ${ }^{22}$ There was statistically insignificant difference $(p=0.828)$ in the DLQI score between different age groups using the one way ANOVA test.

\section{References}

1. Sanchez NP, Pathak MA, Sato S, Fitzpatrick TB, Sanchez JL, Mihm MC, Jr. Melasma: a clinical, light microscopic, ultrastructural, and immunofluorescence study. J Am Acad Dermatol 1981;4(6):698-710. https://doi.org/10.1016/ S0190-9622(81)70071-9

2. Muallem MM, Rubeiz NG. Physiological and biological skin changes in pregnancy. Clin Dermatol 2006;24(2):80-3. https://doi. org/10.1016/j.clindermatol.2005.10.002

3. Carruthers R. Chloasma and oral contraceptives. Med J Aust 1966;2(1):17-20. https://doi. org/10.5694/j.1326-5377.1966.tb73370.x

4. Victor FC, Gelber J, Rao B. Melasma: a review. J Cutan Med Surg2004;8(2):97-102. https://doi. org/10.1007/s10227-004-0158-9
There was no significant difference in the DLQI scores between males and females $(p=0.162)$ which was similar to the classic study by Finlay and Khan which also showed no significant difference in skin disease between two gender. ${ }^{12}$ In our study, the quality of life was significantly impaired most in those who had studied below SLC with mean DLQI= $12.61 \pm 6.05$ $(p=0.014)$. In our study, farmers had lowest mean DLQI $(5 \pm 2.55)$, whereas those involved in Jobs had higher mean DLQI (11.28 \pm 5.97). There was no significant correlation between occupation and DLQI $(p=0.176)$ which was in contrary to the study from Thailand which showed significant correlation of monthly personal income and total DLQI score. ${ }^{23}$ There was no significant correlation in age, duration of disease, sex, marital status, race, distribution of disease and MASI. There was a weak correlation between the DLQI and severity of melasma $(p=0.317)$. This finding was similar to the results of other study where only moderate correlation was seen between Quality of Life and MASI. ${ }^{24}$

\section{Conclusion}

In this study, the mean DLQI score was 10.9, thus indicating "very large effect on patient's life". The mean MASI score was 6.6. It was found that there was weak correlation between severity of disease and DLQI scores. Thus, the impact of melasma on quality of life in relation to melasma severity needs to be assessed, so that psychological support, and appropriate counselling can be provided to the patients. This will help in enhancing the patient care, outcome and incorporation of psychological aspect in future health programs as well.

5. Grimes PE. Melasma: etiologic and therapeutic considerations. Arch Dermatol 1995;131(12):1453-7. https://doi.org/10.1001/ archderm.1995.01690240119022

6. Im S, Moro O, Peng F, Medrano EE, Cornelius J, Babcock $G$, et al. Activation of the cyclic AMP pathway by alpha-melanotropin mediates the response of human melanocytes to ultraviolet $B$ radiation. Cancer Res. 1998;58(1):47-54

7. Kim EH, Kim YC, Lee ES, Kang HY. The vascular characteristics of melasma. J Dermatol Sci 2007;46(2):111-6. https://doi.org/10.1016/j. jdermsci.2007.01.009

8. Taylor SC. Epidemiology of skin diseases in ethnic populations. Dermatol Clin 2003;21(4):601-7. https://doi.org/10.1016/S0733-8635(03)00075-5 
9. Guinot C, Cheffai S, Latreille J, Dhaoui M, Youssef $\mathrm{S}$, Jaber $\mathrm{K}$, et al. Aggravating factors for melasma: a prospective study in 197 Tunisian patients. Journal of the European Academy of Dermatology and Venereology. 2010;24(9):1060-9. https://doi. org/10.1111/j.1468-3083.2010.03592.x

10. Pawaskar MD, Parikh P, Markowski T, McMichael AJ, Feldman SR, Balkrishnan R. Melasma and its impact on health-related quality of life in Hispanic women. Journal of Dermatologic Treatments. 2007;18(1):5-9. https://doi. org/10.1080/09546630601028778

11. Fortune DG, Main CJ, O'Sullivan TM, Griffiths CE. Quality of life in patients with psoriasis: the contribution of clinical variables and psoriasis-specific stress. British Journal of Dermatology. 1997;137(5):755-60. https://doi. org/10.1111/j.1365-2133.1997.tb01113.x

12. Finlay AY, Khan GK. Dermatology Life Quality Index (DLQI)--a simple practical measure for routine clinical use. Clinical and Expermintal Dermatology. 1994;19(3):210-6. https://doi. org/10.1111/j.1365-2230.1994.tb01167.x

13. Shrestha D, Gurung D, Rosdahl I. Prevalence of skin diseases and impact on quality of life in hilly region of Nepal. Journal of Institute of Medicine Journal. 2012;34(3):44-9. https://doi. org/10.3126/jiom.v34i3.8917

14. Harumi O, Goh CL. The effect of melasma on the quality of life in a sample of women living in Singapore. J Clin Aesthet Dermatol 2016;9(1):21.

15. Freitag FM, Cestari T, Leopoldo L, Paludo P, Boza J. Effect of melasma on quality of life in a sample of women living in southern Brazil. J Eur Acad Dermatol Venereol 2008;22(6):655-62. https:// doi.org/10.1111/j.1468-3083.2007.02472.x

16. Ali R, Aman S, Nadeem M, Kazmi AH. Quality of life in patients of melasma. Journal of Pakistan Association of Dermatology. 2016;23(2):143-8.

17. Morgaonkar M, Gupta S, Vijay A, Jain SK, Sharma M, Agarwal S. Melasma: Its impact on quality of life. Pigment International. 2017;4(1):39. https:// doi.org/10.4103/2349-5847.208298
18. Amatya B, Jha AK, Shrestha S. Frequency of different types of facial melanoses referring to the Department of Dermatology and Venereology, Nepal Medical College and Teaching Hospital in 2019, and assessment of their effect on health- related quality of life. BMC Dermatology. 2020;20(1):4. https://doi.org/10.1186/s12895020-00100-3

19. Ingordo V, Cazzaniga S, Gentile C, lannazzone S, Cusano F, Naldi L. Dermatology Life Quality Index score in vitiligo patients: a pilot study among young Italian males. Giornale Italiano Dermatologia Venereologia. 2012;147(1):83-90.

20. Suthanther C, Bubna A, Sankarasubramanian A, Veeraraghavan $M$, Rangarajan $S$, Muralidhar K. A clinical study of melasma and assessment of Dermatology Life Quality Index at a tertiary health care center in South India. Pigment International. 2016;3(2):77. https://doi.org/10.4103/23495847.196298

21. Pichardo R, Vallejos Q, Feldman SR, Schulz MR, Verma A, Quandt SA, et al. The prevalence of melasma and its association with quality of life in adult male Latino migrant workers. Int J Dermatol 2009;48(1):22-6. https://doi.org/10.1111/j.13654632.2009.03778.x

22. Uyanikoglu H, Aksoy M. Quality of life in patients with melasma in Turkish women. Dermatol Reports. 2017;9(2). https://doi.org/10.4081/ dr.2017.7340

23. Leeyaphan C, Wanitphakdeedecha R, Manuskiatti W, Kulthanan K. Measuring melasma patients' quality of life using willingness to pay and time trade-off methods in Thai population. BMC Dermatol 2011;11:16. https://doi. org/10.1186/1471-5945-11-16

24. Dominguez $A R$, Balkrishnan R, Ellzey AR, Pandya AG. Melasma in Latina patients: cross-cultural adaptation and validation of a quality-oflife questionnaire in Spanish language. J Am Acad Dermatol 2006;55(1):59-66. https://doi. org/10.1016/j.jaad.2006.01.049 